\begin{tabular}{|c|c|c|}
\hline Case Reports & \multicolumn{2}{|c|}{ Case Rep Gastroenterol 2015;9:266-271 } \\
\hline $09 y$ & $\begin{array}{l}\text { DOI: 10.1159/000437290 } \\
\text { Publisnea onine. Jury Z9, } 2015\end{array}$ & $\begin{array}{l}\text { (C) } 2015 \text { S. Karger AG, Basel } \\
1662-0631 / 15 / 0092-0266 \$ 39.50 / 0 \\
\text { www.karger.com/crg }\end{array}$ \\
\hline & \multicolumn{2}{|c|}{$\begin{array}{l}\text { This is an Open Access article licensed under the terms of the Creative Commons } \\
\text { Attribution-NonCommercial } 3.0 \text { Unported license (CC BY-NC) (www.karger.com/OA } \\
\text { license), applicable to the online version of the article only. Distribution permitted for non } \\
\text { commercial purposes only. }\end{array}$} \\
\hline
\end{tabular}

\title{
Metastatic Fibrolamellar Hepatocellular Carcinoma to the Pancreas
}

\author{
Nicolas A. Villa ${ }^{a}$ Rahul Pannala ${ }^{a}$ Douglas O. Faigel ${ }^{a}$ \\ Danielle J. Haakinson ${ }^{b}$ Nitin Katariya ${ }^{c}$ Ramesh Ramanathan ${ }^{d}$ \\ Dawn Jaroszewski $^{\mathrm{e}}$ Thomas K. Lidner ${ }^{f}$ Thomas Byrne $^{a}$ \\ ${ }^{a}$ Division of Gastroenterology and Hepatology, ${ }^{b}$ Department of General Surgery, ${ }^{c}$ Division \\ of Transplant Surgery, ${ }^{\mathrm{d}}$ Division of Hematology and Oncology, ${ }^{\mathrm{e}}$ Division of Cardiothoracic \\ Surgery, and ${ }^{\mathrm{f} D e p a r t m e n t}$ of Pathology, Mayo Clinic Arizona, Scottsdale, Ariz., USA
}

\section{Key Words}

Fibrolamellar hepatocellular carcinoma · Metastasis · Liver transplantation

\begin{abstract}
Fibrolamellar hepatocellular carcinoma (FL-HCC) is a rare variant of hepatocellular carcinoma, usually presenting in the younger population ( $<40$ years) without underlying liver disease. Although it has a better prognosis than hepatocellular carcinoma, it has a high rate of recurrence months to years after primary resection. While sites of recurrence usually involve the liver, regional lymph nodes, peritoneum, and lung, metastasis to the pancreas is extremely rare, with only 2 other cases reported in the literature. We present the case of a 46 -year-old patient with metastatic FL-HCC to the pancreas 30 years after diagnosis and 26 years since his last resected liver recurrence.

(c) 2015 S. Karger AG, Basel
\end{abstract}

\section{Introduction}

Fibrolamellar hepatocellular carcinoma (FL-HCC) is a rare primary liver tumor, usually presenting in the younger population ( $<40$ years) [1,2], which was first described by Edmondson [3] in 1956. It is characterized histologically by well-differentiated malignant hepatic cells with abundant eosinophilic and granular cytoplasm due to the presence of numerous mitochondria, and by the presence of fibrous stroma arranged in thin parallel lamellae interspersed between tumor cells [1]. While it is a variant of HCC, it does not present in

KARGER 125/s $\begin{aligned} & \text { Nicolas A. Villa } \\ & \text { Division of Gastroenterology and Hepatology } \\ & \text { Mayo Clinic Arizona, 13400 E Shea Blvd } \\ & \text { Scottsdale, AZ 85259 (USA) } \\ & \text { E-Mail nvillagastro@gmail.com }\end{aligned}$


Villa et al.: Metastatic Fibrolamellar Hepatocellular Carcinoma to the Pancreas

patients with underlying liver disease $[1,4]$ and is associated with a better prognosis than conventional HCC $[2,4]$. Presenting symptoms are nonspecific, and involve abdominal pain, weight loss, and malaise. Mild elevations in liver transaminases as well as alkaline phosphatase can be present. In contrast to conventional HCC, it generally does not produce $\alpha$ fetoprotein (AFP) [1]. Instead, it has been associated with elevations in neurotensin levels [5]. Even though surgery is the standard of care, it has a high rate of recurrence months to years after primary resection (up to $80 \%$ in 5 years) [4]. While sites of recurrence usually include the liver, regional lymph nodes, peritoneum, and lung [6], metastasis to the pancreas is extremely rare, with only 2 other cases reported in the literature to our knowledge [7, 8]. We present the case of a 46-year-old patient with metastatic FL-HCC to the pancreas 30 years after he had first been diagnosed and 26 years since his last resected liver recurrence.

\section{Case Presentation}

This is a 46-year-old male with a previous history of FL-HCC diagnosed in 1985 when he was 16 years old. At that time he underwent a routine physical examination, where he was noted to have a positive skin test for tuberculosis. While isoniazid was being considered for treatment, he was found to have elevated liver function tests, which led to further imaging where he was found to have a mass in the liver. Biopsies showed FL-HCC. He underwent liver resection in 1985 and subsequently a liver transplant in 1989 after his FL-HCC had recurred. In 2000 he was found to have hepatitis C, genotype 1b, presumably from his blood transfusions at the time of his previous surgeries. He had done well since his liver transplantation until August 2014, when a left lung nodule $3 \mathrm{~cm}$ in size was noted on a PET CT, in addition to a 2-cm borderline hypermetabolic lesion in the tail of the pancreas. The liver was normal. He underwent a CT-guided biopsy of the left lung that showed metastatic FL-HCC. Subsequent MRI showed a 2.6-cm hyperenhancing round mass in the tail of the pancreas (fig. 1). The patient was then referred for evaluation and diagnosis of the pancreatic mass by endoscopic ultrasound-guided fine-needle aspiration (EUS-FNA).

On physical examination, he had no significant findings. Laboratory tests were normal, except for a creatinine level of $1.3 \mathrm{mg} / \mathrm{dl}$, ALT of $57 \mathrm{IU} / \mathrm{l}$, and a hepatitis C viral load of 1.7 million copies. The AFP level was $3.2 \mathrm{ng} / \mathrm{ml}$. He was on cyclosporine and mycophenolate mofetil for liver transplant immunosuppression. On EUS, a $3.5 \times 3.0 \mathrm{~cm}$ isoechoic heterogeneous well-defined round mass with small cystic spaces within was visualized in the tail of the pancreas (fig. 2). FNA with a 19-gauge needle yielded a bloody sample without a core. This prompted the use of a 25-gauge needle, obtaining adequate specimens, and pathology revealed metastatic FL-HCC (fig. 3). The patient was then referred to surgery for resection of his lung nodule and pancreatic tail mass. Chemotherapy was not considered, as both his lesions were deemed resectable. He had a simultaneous left-lung video-assisted thoracoscopic surgery wedge resection and distal pancreatectomy with splenectomy (fig. 4). He had an uneventful recovery. He has now initiated hepatitis $\mathrm{C}$ treatment with ledipasvir/sofosbuvir and ribavirin for 12 weeks.

\section{Discussion}

FL-HCC is a rare tumor, accounting for $<1 \%$ of HCC in the USA [2]. Although recurrence and metastasis are common in this type of tumor (60-70\%) [4, 9], metastasis to the pancreas is extremely rare. In our patient, it recurred 30 years after he had first been diagnosed 
Villa et al.: Metastatic Fibrolamellar Hepatocellular Carcinoma to the Pancreas

and 26 years since his last liver recurrence, which was treated with a liver transplant. His AFP level was normal. In contrast to conventional HCC, AFP levels in FL-HCC are usually normal, although elevated levels have been reported in up to $25 \%$ of patients with FL-HCC $[1,10]$.

To date, this is the third case reported of metastatic FL-HCC to the pancreas. Although recurrence can develop months to years after resection, this is the longest 'recurrence-free period' reported in the literature to our knowledge. Lifelong surveillance should be considered in this type of tumor, due to its propensity to recur many years after first presentation.

In our patient, histopathology from the EUS-FNA of the pancreatic mass showed morphologic features of tumor cells compatible with metastasis from the patient's known FLHCC with expression of hepatocyte-specific antigen, glutamine synthetase, glypican-3, and positive CD34 in a canalicular pattern. The surgical pathology from the resected specimens showed focal thin fibrous bands within the metastatic foci; however, definitive diagnostic features of a fibrolamellar variant of HCC were not identified within the metastatic lesions. FL-HCC has certain histologic features that distinguish it from several other tumors and conventional HCC. These include the presence of sheets of large polygonal or spindle-shaped tumor cells with abundant granular eosinophilic cytoplasm, prominent nuclei, and paucicellular fibrous stroma arranged in thin parallel lamellae around tumor cells. Round to oval cytoplasmic 'pale' bodies devoid of nucleus and intracytoplasmic hyaline droplets as well as an increased number of mitochondria have also been reported $[1,11]$. Immunohistochemical studies have found that FL-HCC expresses markers associated with biliary (CK7 and epithelial membrane antigen) and hepatic (hepar-1 and glypican-3) differentiation as well as markers associated with hepatic stem cells (CD133 and CD44) that help differentiate it from conventional HCC $[12,13]$.

In our patient, MRI showed, in addition to the nodule in the left lower lobe, a $2.2 \times 2.6$ $\mathrm{cm}$ well-defined round mass in the tail of the pancreas visualized in the arterial phase, with decreased enhancement in the portal venous phase suggesting vascularity. Although the enhancement appeared similar to the lesion in the lung, there was no fibrous central scar which is one of the main characteristics of this lesion when presenting as a primary liver tumor [14]. Other imaging features associated with FL-HCC are the presence of calcifications, which can be seen in 40-68\% of cases [15].

Due to its indolent clinical course, the diagnosis of FL-HCC usually occurs at an early stage, when primary resection or transplantation can be offered [2]. To date, the treatment of choice is surgical resection, with 5-year survival rates reported as high as $70-85 \%$ after partial hepatectomy $[4,16,17]$. Although median survival rates after transplantation have been reported to be only 28-32 months, and there is a 5-year survival of about $35 \%$, these data come from the 1990s, when less strict criteria were used for liver transplantation, likely explaining the poorer outcomes $[16,18,19]$. More recent studies report a 5-year survival between $50-60 \%$ after liver transplantation $[17,20,21]$. The overall prognosis of FL-HCC compared to conventional HCC is $30-34$ vs. $7-16 \%[2,20]$, although this largely depends on staging at the time of diagnosis, the presence of cirrhosis, and whether surgery was performed. In fact, a recent meta-analysis found that there seemed to be no difference in survival between FL-HCC and conventional HCC in noncirrhotic patients or when transplantation was used as the therapeutic option [17].

Although recurrences and metastasis are common, surgery is still the treatment of choice for resectable metastasis, given the lack of other effective treatment options such as chemotherapy $[4,6]$. However, chemotherapy and radiation are still options for advanced cases where surgery is not an option $[6,21,22]$. 
Villa et al.: Metastatic Fibrolamellar Hepatocellular Carcinoma to the Pancreas

In conclusion, this is the third reported case of metastatic FL-HCC to the pancreas. Interestingly, in this patient, metastasis occurred 30 years from first diagnosis and 26 years since his last resected liver recurrence. Attention to the radiologic findings on MRI and EUS may alert the clinician when a mass in the pancreas appears in the setting of a previous history of FL-HCC. Lifelong surveillance should be considered in this type of tumor, due to its propensity to recur years after its first presentation. Because of its indolent clinical course, resection of metastatic lesions is the treatment of choice.

\section{References}

1 Craig JR, Peters RL, Edmondson HA, et al: Fibrolamellar carcinoma of the liver: a tumor of adolescents and young adults with distinctive clinico-pathologic features. Cancer 1980;46:372-379.

-2 El Serag HB, Davila JA: Is fibrolamellar carcinoma different from hepatocellular carcinoma? A US population-based study. Hepatology 2004;39:798-803.

-3 Edmondson HA: Differential diagnosis of tumors and tumor-like lesions of liver in infancy and childhood. Arch Dis Child 1956;1:168-186.

4 Stipa F, Yoon SS, Liau KH, Fong Y, Jarnagin WR, D’Angelica M, et al: Outcome of patients with fibrolamellar hepatocellular carcinoma. Cancer 2006;106:1331-1338.

5 Collier NA, Weinbren K, Bloom SR, et al: Neurotensin secretion by fibrolamellar carcinoma of the liver. Lancet 1984;1:538-540.

6 Epstein BE, Pajak TF, Haulk TL, Herpst JM, Order SE, Abrams RA: Metastatic nonresectable fibrolamellar hepatoma: prognostic features and natural history. Am J Clin Oncol 1999;22:22-28.

7 Wojcicki M, Lubikowski J, Post M, et al: Aggressive surgical management of recurrent lymph node and pancreatic head metastasis of resected fibrolamellar hepatocellular carcinoma: a case report. JOP 2012;13:529-532.

-8 Thirabanjasak D, Sosothikul D, Mahayosnond A, Thorner PS: Fibrolamellar carcinoma presenting as a pancreatic mass: case report and review of the literature. J Pediatr Hematol Oncol 2009;31:370-372.

-9 Ichikawa T, Federle MP, Grazioli L, et al: Fibrolamellar hepatocellular carcinoma: pre and posttherapy evaluation with CT and MR imaging. Radiology 2000;217:145-151.

10 Matsuda M, Amemiya H, Kawaida H, et al: Typical fibrolamellar hepatocellular carcinoma in a Japanese boy: report of a case. Surg Today 2014;44:1359-1366.

11 Berman MA, Burnham JA, Sheahan DG: Fibrolamellar carcinoma of the liver: an immunohistochemical study of nineteen cases and a review of the literature. Hum Pathol 1988;19:784-794.

-12 Zenali MJ, Tan D, Li W, Dhingra S, Brown RE: Stemness characteristics of fibrolamellar hepatocellular carcinoma: immunohistochemical analysis with comparisons to conventional hepatocellular carcinoma. Ann Clin Lab Sci 2010;40:126-134.

13 Ward SC, Waxman S: Fibrolamellar carcinoma: a review with focus on genetics and comparison to other malignant primary liver tumors. Semin Liver Dis 2011;31:61-70.

14 Ganeshan D, Szklaruk J, Kundra V, et al: Imaging features of fibrolamellar hepatocellular carcinoma. Am J Roentgenol 2014;202:544-552.

-15 Ichikawa T, Federle MP, Grazioli L, Madariaga J, Nalesnik M, Marsh W: Fibrolamellar hepatocellular carcinoma: imaging and pathologic findings in 31 recent cases. Radiology 1999;213:352-361.

16 Mavros MN, Mayo SC, Hyder O, Pawlik TM: A systematic review: treatment and prognosis of patients with fibrolamellar hepatocellular carcinoma. J Am Coll Surg 2012;215:820-830.

17 Njei B, Konjeti V, Ditah I: Prognosis of patients with fibrolamellar hepatocellular carcinoma versus conventional hepatocellular carcinoma: a systematic review and meta-analysis. Gastrointest Cancer Res 2014;7:49-54.

18 Ringe B, Wittekind C, Weimann A, et al: Results of hepatic resection and transplantation for fibrolamellar carcinoma. Surg Gynecol Obstet 1992;175;299-305.

19 Pinna AD, Iwatsuki S, Lee RG, et al: Treatment of fibrolamellar hepatoma with subtotal hepatectomy or transplantation. Hepatology 1997;26:877-883.

20 Eggert T, McGlynn KA, Duffy A, et al: Epidemiology of fibrolamellar hepatocellular carcinoma in the USA, 2000-2010. Gut 2013;62:1667-1668.

21 Maniaci V, Davidson BR, Rolles K, et al: Fibrolamellar hepatocellular carcinoma: prolonged survival with multimodality therapy. Eur J Surg Oncol 2009;35:617-621.

22 Bower M, Newlands ES, Habib N: Fibrolamellar hepatocellular carcinoma responsive to platinum based combination chemotherapy. Clin Oncol (R Coll Radiol) 1996;8:331-333. 


\begin{tabular}{ll|l} 
Case Reports in & \multicolumn{2}{l}{} \\
\cline { 2 - 3 } Gastroenterology & Case Rep Gastroenterol 2015;9:266-271 \\
\cline { 2 - 3 } & DOI: 10.1159/000437290 & $\begin{array}{l}\text { ○ 2015 S. Karger AG, Basel } \\
\text { www.karger.com/crg }\end{array}$ \\
\cline { 2 - 3 } & Villa et al.: Metastatic Fibrolamellar Hepatocellular Carcinoma to the Pancreas
\end{tabular}

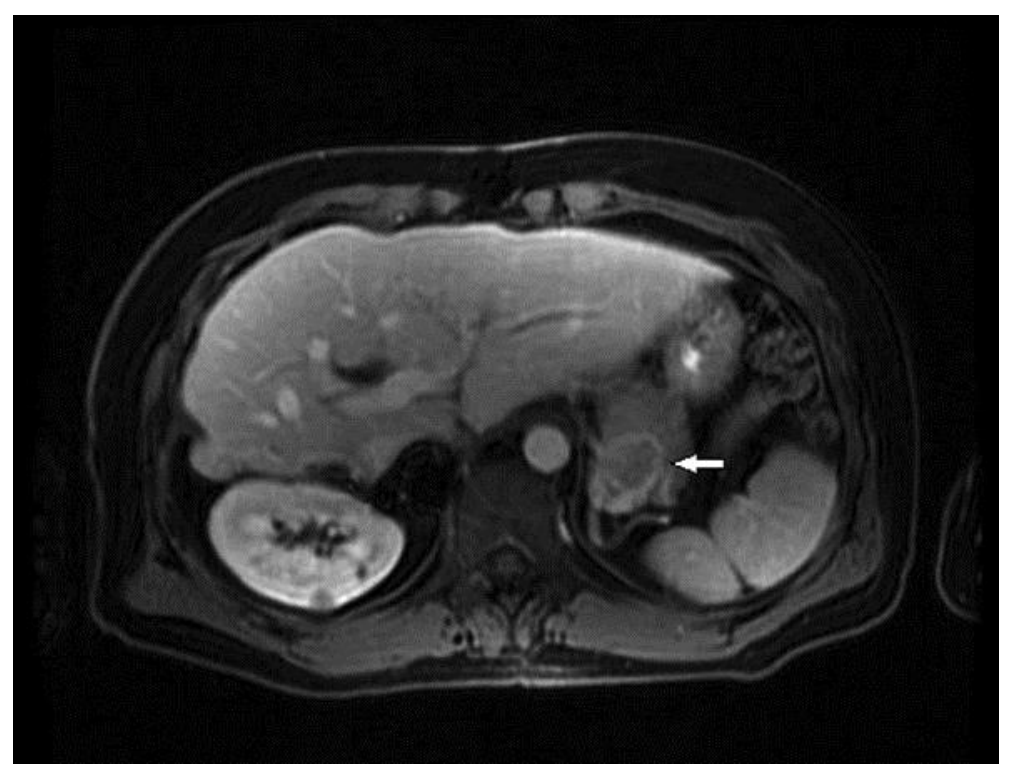

Fig. 1. MRI. A $2.2 \times 2.6 \mathrm{~cm}$ hyperenhancing round mass in the tail of the pancreas (arrow). The mass was visualized in the arterial phase, with decreased enhancement in the portal venous phase suggesting vascularity.

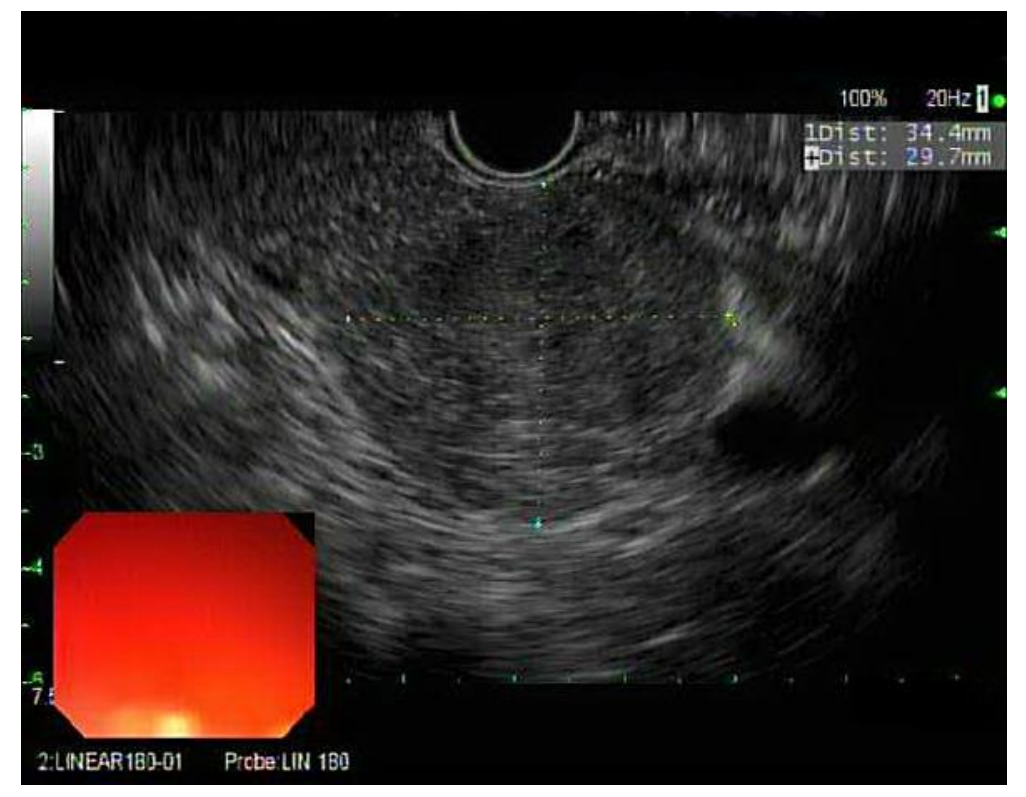

Fig. 2. EUS. A $3.5 \times 3.0 \mathrm{~cm}$ isoechoic heterogeneous well-defined round mass with small cystic spaces within was seen in the tail of the pancreas. 


\begin{tabular}{|c|c|c|}
\hline \multirow{3}{*}{$\begin{array}{r}\text { Case Reports in } \\
\text { Gastroenterology }\end{array}$} & \multirow{2}{*}{\multicolumn{2}{|c|}{ Case Rep Gastroenterol 2015;9:266-271 }} \\
\hline & & \\
\hline & DOI: $10.1159 / 000437290$ & $\begin{array}{l}\text { (c) } 2015 \text { S. Karger AG, Basel } \\
\text { www.karger.com/crg }\end{array}$ \\
\hline
\end{tabular}
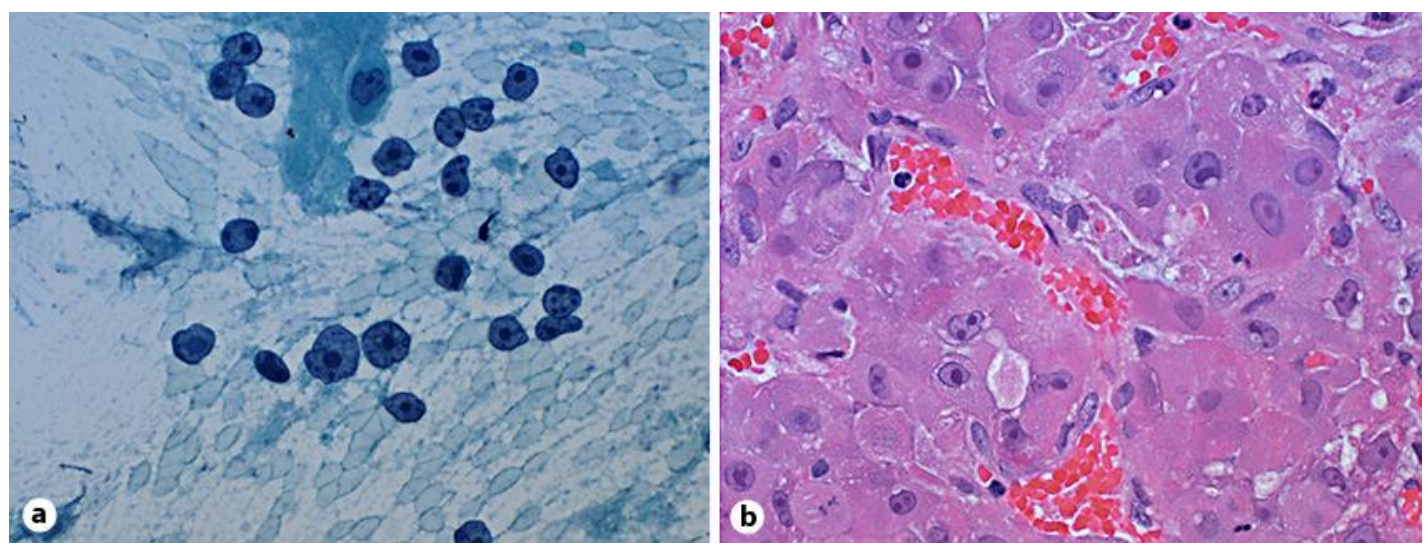

Fig. 3. Histopathology of FL-HCC. a Pap stain of an aspirate smear $(\times 400)$ showing tumor cells with abundant cytoplasm, many with stripped cytoplasm and prominent macronucleoli. b Hematoxylin and eosin stain of a cell block $(\times 400)$ showing tumor cells with abundant eosinophilic cytoplasm and prominent macronucleoli.

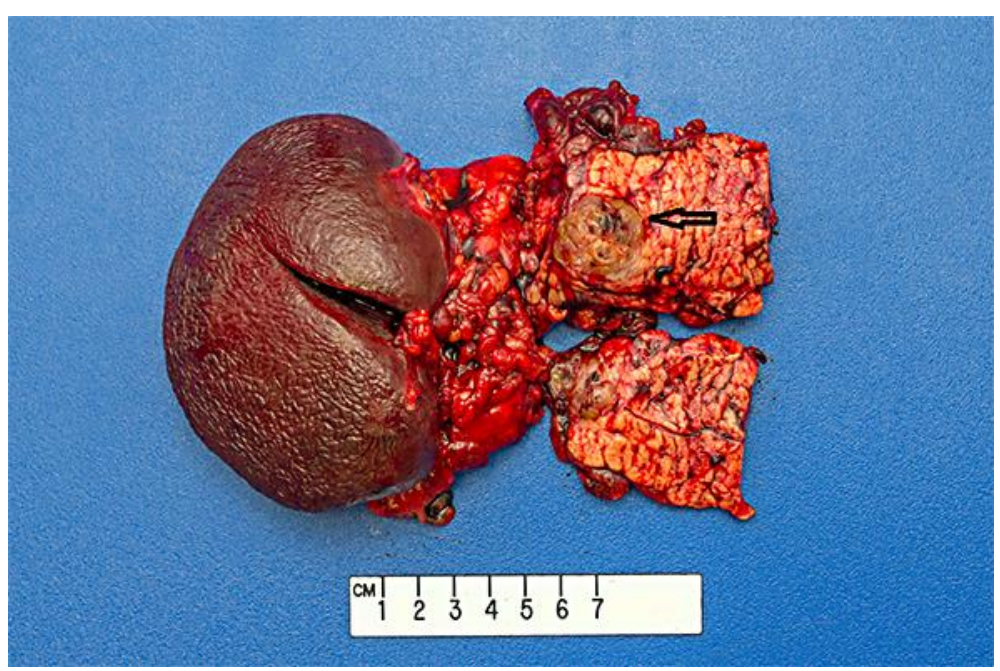

Fig. 4. Gross specimen of the metastatic pancreatic mass (arrow). 